the operation. It is believed that these cases are few in number and that the explanation for the response has yet to be provided.

\section{Summary}

The value of lumbar sympathectomy for intermittent claudication is disputed. Improvement would imply persistent release of collateral or vasomotor tone. It is doubtful whether afferent fibres are carried in the sympathetic trunk in sufficient number to be of significance. Thirty-one patients having 40 lumbar sympathectomies for intermittent claudication were studied before and 10 to 14 days after operation by strain-gauge plethysmography. Measurements were made of the resting flow, of the peak flow and time of its development during reactive hyperaemia, and of the distal arterial pressure in the calf muscle. No statistically significant increase could be demonstrated after sympathectomy in any of these parameters in the group as a whole. Nor could significant change be shown according to the clinical response to the operation, to the severity or duration of the symptoms, or to the site of the occlusion or extent of the disease. The flows both before and after sympathectomy were higher in the group showing clinical improvement, suggesting that spontaneous remission is more likely to occur when the disease is less severe. It is considered that there is no objective evidence of consistent haemodynamic benefit from lumbar sympathectomy for intermittent claudication.

\section{REFERENCES}

Abramson, D. I., and Ferris, E. B. (1940). Amer. Heart 7., 19, 541. Barcroft, H. (1952). Brit. med. Bull., 8, 363

Bar (1963). In Handbook of Physiology, Section 2: Circulation, vol 2 p. 1353, edited by W. F. Hamilton and P. Dow. Williams and Wilkins, Baltimore.

and Dornhorst, A. C. (1949). 7. Physiol. (Lond.), 109, 402.

- and Edholm, O. G. (1946). Lancet, 2, 513.

Beaconsfield, P. (1954). Ann. Surg., 140, 786.

Bentley, F. H. (1958). Amer. 7. Surg., 96, 193

Blair, D. A., Glover, W. E., Greenfield, A. D. M., and Roddie, I. C. (1959). F. Physiol. (Lond.), 149, 614.

Bloor K. and Roddie, I. C. (1961). Circulat. Res., 9, 264.

Brigden, W., Howarth. S.. and Sharpey-Schafer, E. P. (1950). Clin. Sci. 9, 79 .
Burton, A. C., and Edholm, O. G. (1955). Man in a Cold Environment, p. 129. Arnold, London

Clarke, R. S. J., Ginsburg, J., and Hellon, R. F. (1958a). 7. Physiol. (Lond.), 140, 318

Hellon, R. F., and Lind, A. R. (1958b). Ibid., 143, 454

Coles, D. R., and Cooper, K. E. (1959). Ibid., 145, 241.

Dornhorst, A. C. (1963). Brit. med. Bull., 19, 137.

and Sharpey-Schafer, E. P. (1951). Clin. Sci., 10, 371.

Echlin, F. (1949). F. Neurosurg., 6, 530

Eichna, A. H., and Evans, R. D. (1936). Bull. Fohns Hopk. Hosp., 68, 450.

Elliot, A. H., and Evans, R. D. (1936). Amer. Heart F., 12, 674.

Folkow, B. (1960). Circulation, 21, 760 .

- (1962). Arch. int. Pharmacodyn., 139, 455.

- Mellander S. and öberg, B. (1961). Acta physiol. scand., 53, 7.

Freeman, L. W., Shumacker, H. B., and Radigan, L. R. (1950). Surgery, 28, 274 .

Gilfillan, R. S. (1958). Ibid., 43, 758.

Gillespie, J. A. (1960). Brit. med. F., 2, 1640

Harris, W. (1936). Ibid., 2, 112.

Hillestad, L. K. (1963). Acta med. scand., 174, 23.

Hilton, S. M. (1959). F. Physiol. (Lond.), 149, 93.

- (1962). Phys. Rev., 42, Suppli. No. 5, p. 265.

Hirsch, L. (1925). Arck. klin. Chir., 137, 281.

Kjellmer. I. (1965). Acta physiol. scand., 63, 460.

Kuntz, A. (1951). Sth. med. Ұ. (Bgham, Ala.), 44, 673.

Kuntz, A. (1951). Sth. med. F. (Bgham, Ala.), 44, 673. .

Lewis, D. H., and Mellander, S. (1962). Acta physiol. scand., 56, 162.

Lewis, T., Pickering, G. W., and Rothschild, P. (1931). Heart,
Longland, C. J. (1953). Ann. roy. Coll. Surg. Engl., 13, 161.

Mackenzie, D. C., and Loewenthal, J. (1962). Surg. Gynec. Obstet., 115, 303

Mason, D. T., and Braunwald, E. (1962). Amer. Heart F., 64, 796.

Myers, K. A. (1964). Angiology, 15, 293.

Patterson, G. C., and Whelan, R. F. (1955). Clin. Sci., 14, 197.

Roddie, I. C., and Shepherd, J. T. (1956). Ibid., 15, 433.

Shepherd, J. T. (1950a). Ibid., 9, 49.

(1950b). I Ibid., 9, 355.

(1950). Ibid., 9, 355. 2,1413

Simeone, F. A. (1950). Surgery, 28, 281.

Singer, A., and Rob, C. (1960). Brit. med. 7., 2, 633.

Smithwick, R. H. (1957). Surgery, 42, 415, 567

Taylor, G. W., and Calo, A. R. (1962). Brit. med. f., 1, 507

Thulesius, O." (1963). Acta physiol. scand., 57, Suppl. No. 199.

Tice, D. A., Reed. G. E., Messina, E. J., Clemente, E., and Redisch, W. (1963). Arch. Surg., 87, 461.

Uvnäs, B. (1960). Physiol. Rev., 40, Suppl. No. 4, p. 69

Van Harreveld, A., and Lindsley, D. L. (1952). Amer. F. Physiol., 171, 447.

Walder, D. N. (1961). 7. Physiol. (Lond.), 159, 70P.

White, J. C. (1954). Arch. Neurol. Psychiat., 71, 1.

Whitney, R. J. (1953). F. Physiol. (Lond.), 121, 1.

Woollard, H. H. (1926). Heart, 13, 319.

Yonce, L. R., Dykers, J. R., and McGee, J. W. (1962). Amer. F. Physiol., 202, 277.

(Part II (Skin Ischaemia) will be printed next week.)

\title{
Vascular Responses in Diabetic Peripheral Neuropathy*
}

\author{
J. A. MOORHOUSE, $\dagger$ M.D. ; S. A. CARTER, $\ddagger$ M.D.; J. DOUPE,§ M.D.
}

Brit. med. F., 1966, 1, 883-888

Degenerative lesions of the peripheral nerves in the extremities of diabetic patients were first described in 1887 by Pryce, who later noted that "these patients are occasionally liable to vasomotor and trophic signs" (Pryce, 1893). The vasomotor signs which he observed were not objectively measured until nearly 50 years later (Shumacker, 1942). Soon thereafter the high frequency of vasomotor disturbances in patients with diabetic neuropathy began to be emphasized by a number of authors (Rundles, 1945 ; Berner, 1952 ; Handelsman et al., 1952 ; Martin, 1953 ; Odel et al., 1955).

Studies of the nature and pathogenesis of the disturbance of peripheral vascular responsiveness in diabetic neuropathy have been controversial and confusing. The abnormalities have been attributed by some (Mendlowitz et al., 1953 ; Megibow et al., 1953) purely to impedance of blood-flow by occlusive vascular disease. Though there is now more general agreement that they can be due entirely to disordered vasomotor control resulting from damage to peripheral autonomic nerve fibres
(Rundles, 1945 ; Doupe and Cherniack, 1950 ; Martin, 1953 ; Odel et al., 1955 ; Bárány, 1955 ; Keen, 1959), there has been no agreement about the nervous mechanisms involved. Doupe and Cherniack (1950), noting that peripheral nerve injuries greatly increase the sensitivity of blood-vessels to adrenaline (Meltzer and Meltzer, 1903 ; Freeman et al., 1934) and to cold (Ascroft, 1937 ; Doupe, 1943 ; Richards, 1946), suggested that the persistent coldness of the feet often seen in neuropathic subjects might be due to denervation hypersensitivity. This suggestion was supported by later authors (Bárány, 1955; Bárány and Cooper, 1957 ; Stone et al., 1961), but has recently

\footnotetext{
* Presented in part at the Fifth Congress of the International Diabetes Federation, Toronto, Ontario, Canada, July 1964 . Supported by
grants from the Medical Research Council of Canada.

† Assistant Professor, Department of Physiology, University of Manitoba, Winnipeg, Canada.

‡ Assistant Professor, Department of Physiology, University of Manitoba, Winnipeg, Canada.

$\$$ Professor, Department of Physiology, University of Manitoba, Winnipeg,
} 
been questioned (Brody and Dixon, 1964). Martin (1953) had a different hypothesis. He observed that, while some of his patients had abnormally cold feet which did not warm in response to body heating, others had warm feet which did not cool in response to body-cooling. He attributed these abnormalities to selective destruction of vasodilator and vasoconstrictor fibres respectively. Finally, Sharpey-Schafer and Taylor (1960), observing abnormal pressor responses to the Valsalva manœuvre and to tilting in patients whom they believed to have normal thermal vasomotor reflexes, suggested that the responsible lesion lay not in the efferent but in the afferent autonomic fibres.

The results of the present studies appear to resolve these conflicting findings and opinions, and to demonstrate that the abnormal vascular responses in diabetic neuropathy are due to loss of controlling sympathetic vasoconstrictor impulses, together with local hypersensitivity to cold and to adrenaline.

\section{Subjects and Methods}

Observations were made on young healthy subjects, on elderly subjects with non-diabetic neuropathy, and on diabetic subjects with and without neurological signs. The healthy subjects were 12 medical students between the ages of 18 and 25 . The elderly subjects were 15 hospital out-patients with treated pernicious anaemia between the ages of 58 and 84 , all but one of whom had sensory loss in the lower limbs. The 43 diabetic subjects ranged in age from 23 to 85 . Two had sensory and reflex loss in both their upper and lower limbs, and 27 in their lower limbs only. The remaining 14 had no neurological signs. Some of the diabetic subjects were in hospital at the time of study, but all were ambulant. None had clinical signs of arterial insufficiency in their feet, and all could maintain digital temperatures at least $5^{\circ} \mathrm{C}$. above room temperature. None had ulcers or inflammatory lesions.

Vasomotor responses to the various test procedures were studied by the continuous recording of digital skin temperatures. All tests were carried out in a room with a temperature constant at 18 to $20^{\circ} \mathrm{C}$. The subjects lay supine, clad only in a light cotton hospital gown. Temperatures were usually recorded from the first and fourth toes of each foot, and from the index and fourth fingers of the right hand. The gauge 32 copperconstantan thermocouples were held in contact with the pads of the digits by narrow strips of adhesive tape over the dorsum of the middle phalanx. Rectal temperature was monitored by means of a thermopile placed approximately $6 \mathrm{~cm}$. above the anal sphincter. Each temperature was automatically plotted on moving paper every 30 seconds by means of a Leeds and Northrup Speedomax type $\mathrm{G}$ recorder.

Studies were made of three aspects of peripheral vascular reactivity-naniely, the reflex vasomotor responses to bodyheating and cooling, the local vasomotor responses to the direct heating and cooling of the digit itself, and the humoral vasomotor response to the subcutaneous injection of adrenaline.

Reflex vasomotor responses to body-heating and cooling were elicited by the method of Gibbon and Landis (1932). Bodyheating was induced by covering the body with warm blankets, leaving only the distal parts of the extremities exposed, and immersing the left hand and forearm in water at 43 to $45^{\circ} \mathrm{C}$. Body-cooling was induced by removing the blankets, and immersing the left hand and forearm in water at 16 to $18^{\circ} \mathrm{C}$. This test was done on all the subjects.

The local vasomotor response to direct cooling was studied by immersing a limb, with the thermocouples attached, in a water-bath at 16 to $18^{\circ} \mathrm{C}$. for 15 to 60 minutes, thereby inducing vasoconstriction, and then removing the sympathetic tone to the digits either by body-heating or by blocking a peripheral nerve trunk with procaine hydrochloride. If the body-heating or the nerve-block caused the temperature of the immersed digits to rise above that of the bath, thus indicating that vasodilatation had occurred, this was interpreted to mean than locally autonomous vasospasm, independent of sympathetic tone, had not been produced. If, on the other hand, the temperature of the digits did not rise, this was interpreted to mean that autonomous vasospasm in response to local cold had been produced. In those subjects whose peripheral vasculature was sensitive to the constricting action of local cold, the effect of local warming was tested by immersing the limb for a few minutes in a water-bath at 43 to $45^{\circ} \mathrm{C}$. These tests were done on six healthy subjects, and on 14 diabetic subjects with neurological signs.

The humoral vasomotor response to adrenaline was tested by injecting $0.2 \mathrm{mg}$. of adrenaline subcutaneously after the induction of maximal digital vasodilatation by body or local heating. This test was done in all the healthy subjects, in five diabetic subjects without neurological signs, and in 12 diabetic subjects with neurological signs.

\section{Results}

\section{Reflex Vasomotor Responses}

Three types of reflex vasomotor response to body-heating and cooling were observed. The incidence of these types of response in the various groups of subjects is shown in the Table. In the young healthy subjects, in most of the elderly subjects with pernicious anaemia, and in some of the diabetic subjects the reflex responses to body-heating and cooling were rapid and full. In some of the subjects with pernicious anaemia and in some of the diabetic subjects the responses were slow and often incomplete. In most of the diabetic subjects with neurological signs, and in a few without, the reflex vasomotor responses were absent. Examples of these types of response are illustrated in Fig. 1.

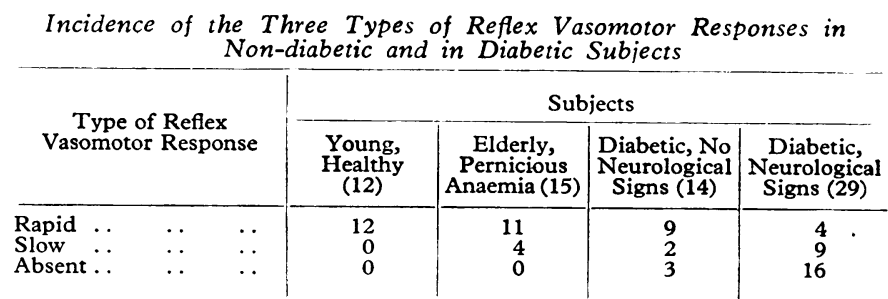

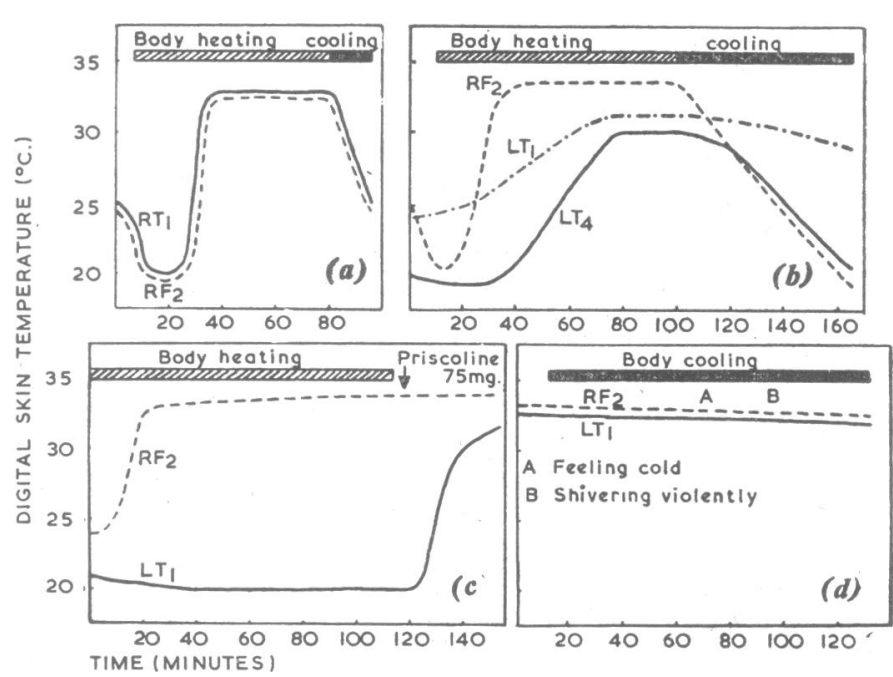

FIG. 1.-Examples of rapid (a), slcw (b), and absent $(c, d)$ reflex vasomotor responses to body-heating and cooling. The charts have been redrawn from the actual skin-temperature records. The abscissae represent time in minutes, the ordinates digital skin temperatures in ${ }^{\circ} \mathrm{C}$ Body-heating is indicated at the top of the charts by the hatched bars, body-cooling by the solid bars. Temperature tracings were obtained from six digits in each case, but only selected representative tracings shown. The particular digit from which the tracing was tracings are indicated by the initials - that is, $\mathrm{RF}_{2}$ refers to the right index finger, LT to the left great toe, etc. 
Normal rapid reflex vasomotor responses in a young healthy subject are shown in Fig. 1 a. Bringing the subject from a warm environment into the constant-temperature room at $20^{\circ} \mathrm{C}$. caused initial vasoconstriction. Body-warming brought about rapid and sustained vasodilatation after a brief latent period, the temperature of the digits reaching well over $30^{\circ} \mathrm{C}$. Body-cooling brought about sharp vasoconstriction.

Slow and less complete reflex vasomotor responses in a 70year-old diabetic man are shown in Fig. $1 b$. This patient had impaired pain sensation below the malleoli. The vasomotor reflexes in his fingers were normal. Vasodilatation in his toes in response to body heating was slow, and the temperature of the digits rose to only $30^{\circ} \mathrm{C}$. Vasoconstriction in the toes in response to body cooling was also slow.

Absent vasomotor responses in two diabetic subjects are shown in Fig. $1 c$ and $d$. A diabetic subject (Fig. $1 c$ ), aged 75 , had slightly diminished pain sensation over the distal half of his feet, and absent vibratory sensation over the distal phalanges of his great toes. The vasomotor reflexes in his fingers were normal. His toes, which were cold when he entered the room, did not show any vasodilatation, despite body-heating for almost two hours. During this time he was perspiring profusely, and his rectal temperature rose to $99.5^{\circ} \mathrm{F}$. (37.5 $\mathrm{C}$.). That the persistent and inappropriate coldness of his feet was purely a functional defect, and that the digital vessels were capable of full and brisk vasodilatation, were demonstrated by the intramuscular injection of $75 \mathrm{mg}$. of the adrenolytic agent tolazoline hydrochloride (Priscol ${ }^{1} ; 2$-benzyl-imidazoline hydrochloride) (Meyer, 1941 ; Doupe and Cherniack, 1950). In a diabetic subject (Fig. $1 d$ ), aged 24, all types of sensation were absent below the knees, and were impaired in the hands and forearms. In contrast to subject $1 c$, both his fingers and toes were warm when he entered the room. Body-cooling for two hours, which caused his rectal temperature to fall to $95.4^{\circ} \mathrm{F}$. $\left(35.2^{\circ} \mathrm{C}\right.$.), and violent shivering, did not cause any vasoconstriction in his hands and feet, which remained warm and flushed.

\section{Local Vasomotor Responses}

In subjects with normal reflex vasomotor responses it was not possible by the application of local cold to the digits to cause autonomous vasospasm-that is, vasospasm which was independent of sympathetic tone. In subjects with absent reflex vasomotor responses, on the other hand, autonomous vasospasm in response to local chilling was readily induced. Examples of these types of response are shown in Fig. 2.

The absence of autonomous vasospasm following exposure to local cold in a young healthy subject is shown in Fig. $2 a$ and $d$. In the experiment depicted in Fig. $2 a$ the left hand and forearm, with digital thermocouples attached, were immersed in a water-bath at $18^{\circ} \mathrm{C}$. The right hand was exposed to the room air. After 50 minutes sympathetic vasomotor tone was inhibited by body-heating. Almost immediately the temperature of the immersed digits increased above that of the water-bath, and when the hand was removed from the bath the temperature of the fingers rose swiftly. The experiment shown in Fig. $2 d$ was analogous, except that sympathetic tone to the immersed left fifth finger was removed by blocking the ulnar nerve at the elbow with procaine. As soon as the block became effective, the temperature of the fifth finger rose above that of the water bath, and upon removal of the hand from the bath the digits became warm and flushed. Similar experiments were carried out on other subjects at bath temperatures ranging from 8 to $28^{\circ}$ C. with the same results. Locally autonomous vasospasm could not be induced in subjects with intact reflex vasomotor control.

${ }^{1}$ Known in the U.S.A. as Priscoline.
In diabetic subjects with absent vasomotor reflexes, on the other hand, autonomous vasospasm in response to local cold could readily be produced. This is shown in Fig. $2 b, c$, and $e$. A diabetic subject (Fig. 2 b), aged 72 , had diminished pain sensation below the ankles, and absent vibratory sensation below the iliac crests. At the beginning of the experiment the temperature of the toes of both feet was about $5^{\circ} \mathrm{C}$. above that of the constant-temperature room. The toes of the right foot, which was exposed to room air throughout the experiment, showed no appreciable response to body-cooling and heating. The left foot was chilled in a water bath at $18^{\circ} \mathrm{C}$. for 25 minutes, then removed from the bath and dried. Then sympathetic vasomotor tone was inhibited by body-heating for 75 minutes. During this time, although the subject was perspiring intensely, his left toes remained cold and blanched. This cold-induced vasospasm, which could not be released by body-warming, and was clearly autonomous and not dependent upon sympathetic vasomotor tone, was readily released when the left foot itself was warmed in a water-bath at $42^{\circ} \mathrm{C}$. Upon removal of the foot from the bath the toes remained warm and flushed. Thus it can be seen that once this limb was locally chilled, or warmed, it remained so, regardless of body temperature.

Another similar experiment is shown in Fig. 2 c. It was performed on diabetic patient $1 d$, whose lack of reflex vasomotor responses is shown in Fig. 1. His fingers and toes were warm when he entered the constant-temperature room. Both became cold, and remained cold, after local chilling in waterbaths at $18^{\circ} \mathrm{C}$., though in the previous experiment (Fig. $1 d$ ) they had remained warm and flushed throughout two hours of profound body-cooling. When the fingers were warmed in a bath at $37^{\circ} \mathrm{C}$. they remained warm. Again the digits maintained either temperature, once established.

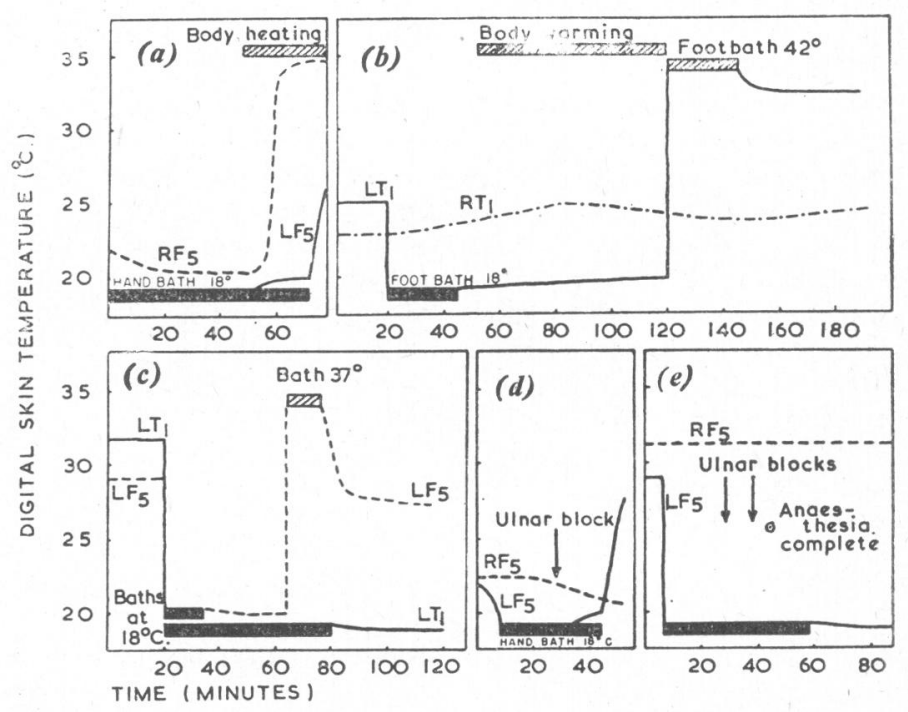

FIG. 2.-Examples of local vasomotor responses to cold in subjects with normal $(a, d)$ and absent $(b, c, e)$ reflex vasomotor responses. Local chilling is indicated at the bottom of the charts by the solid bars. Otherwise the design of the charts is the same as in Fig. 1.

Fig. $2 e$ shows an analogous experiment on the same subject, employing a nerve-block. During immersion of the left hand in a water-bath at $18^{\circ} \mathrm{C}$. complete anaesthesia was produced in the left fifth finger by injecting procaine around the ulnar nerve at the elbow. The temperature of the finger did not increase, and when it was removed from the water-bath it remained cold and blanched. This result is to be contrasted with that of the same experiment in a healthy subject in the immediately preceding panel (Fig. $2 d$ ). Again it can be seen that, in a subject with absent vasomotor reflexes, once vasospasm is induced by local cold it is self-sustaining and withstands removal of any possible sympathetic tone. 


\section{Humoral Vasomotor Responses}

Examples of the vasomotor response to the subcutaneous injection of $0.2 \mathrm{mg}$. of adrenaline are shown in Fig. 3. The injection was given after maximum vasodilatation had been produced by body or local heating. In subjects whose vasomotor reflexes were normal there was no detectable vasoconstrictor response to this dose of adrenaline (Fig. $3 a$ ). In subjects with impaired (Fig. $3 b$ ) or absent (Fig. $3 c$ and $d$ ) vasomotor reflexes, on the other hand, there was a marked and prolonged vasoconstrictor response to this dose of adrenaline.

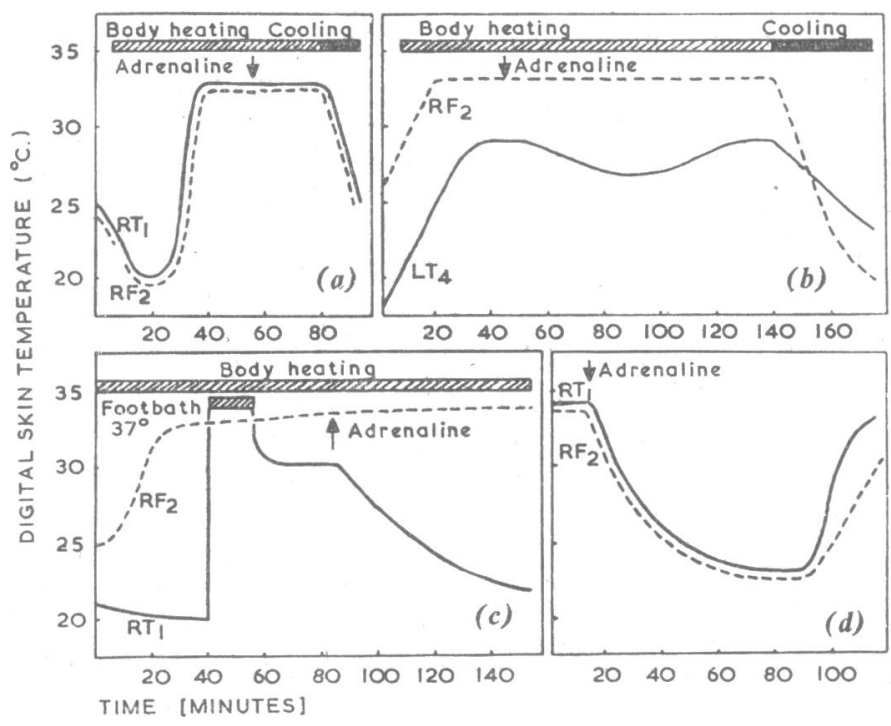

FIG. 3.-Examples of humoral vasomotor responses to adrenaline in sub;ects with normal $(a)$, delayed $(b)$, and absent $(c, d)$ reflex vasomotor responses. The design of the charts is the same as in Fig. 1.

The experimen:s s'n... in Fig. 4 suggest that the effect of adrenaline in digits wis absent vasomotor reflexes is relatively transient, and that the vasoconstriction which occurs is initiated by adrenaline, but maintained by the cooling of the digits that results from the reduction in blood-flow. They were performed on diabetic subject $1 d$ (see also Figs. $1 d, 2 c$ and $e$, and $3 d$ ). Immersion of the left leg in a water-bath at $40^{\circ} \mathrm{C}$. before and for 20 minutes after the injection of adrenaline (Fig. 4 a) did not inhibit the vasoconstrictor response. However, when

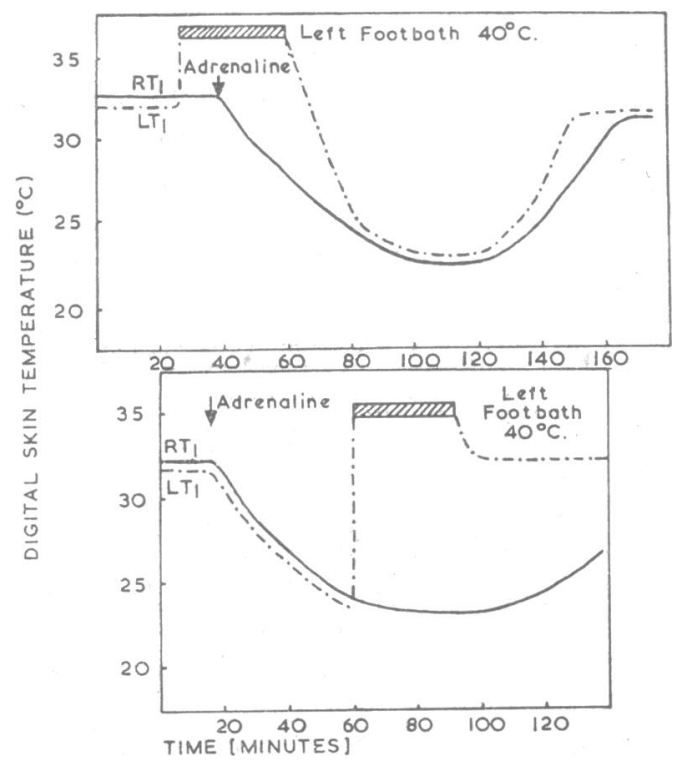

FIg. 4.-Effects of local warming, indicated by the broken bars, upon the augmented vasoconstrictor response to adrenaline which occurs in digits with
absent reflex vasomotor responses. The design of the charts is the same as in Fig. 1. immersion of the foot in the warm bath was delayed until 40 minutes after the injection of adrenaline (Fig. 4 b) the vasoconstriction was terminated.

\section{Discussion}

In a limb with an intact nerve-supply cutaneous vasomotor tone is related to the requirements of internal temperature homoeostasis, and not to the local metabolic requirements of the skin. This tone is governed by the thermotaxic centre in the hypothalamus (Pickering, 1932). The major afferent stimulus to the thermotaxic centre is the temperature of the blood reaching it from the periphery, though afferent-nerve impulses induced by the application of heat and cold to the skin also have an effect (Pickering, 1932, 1958 ; Kerslake and Cooper, 1950). Efferent stimuli from the thermotaxic centre are transmitted to the cutaneous blood-vessels along sympathetic fibres in the peripheral nerves. It is generally agreed that these stimuli cause vasoconstriction, and that there are no cutaneous vasodilator fibres (Gaskell, 1956; Daly, 1962). Cutaneous vasomotor tone, as well as the brisk vasomotor reflexes which normally follow temperature stimuli applied to distant parts of the body, is dependent upon the activity of this reflex arc. The present experiments are in agreement with those of others (Fatherree and Allen, 1938) in indicating that if a limb is acutely deprived of sympathetic vasoconstrictor impulses, as by peripheral nerve-block, the cutaneous vessels dilate, and do not constrict appreciably in response either to general body-cooling or to the local application of cold.

In a limb which has been deprived of its nerve-supply for a period of time sufficient for the sympathetic vasomotor fibres to have degenerated the situation is different. Reflex vasomotor responses to body-heating and cooling still do not occur. Now, however, the cutaneous blood-vessels do exhibit autonomous tone, and this tone does depend directly upon the metabolic needs of the skin as influenced by local temperature (Freeman, 1935 ; Freeman and Zeller, 1937), and not upon the need of the body as a whole to conserve or lose heat. The cutaneous vasculature becomes sensitive to local cold (Ascroft, 1937 ; Doupe, 1943 ; Richards, 1946), so that vasoconstriction can readily be induced by chilling the skin, even though a drop in general body temperature causes no vasoconstrictor response. The vessels also are sensitive to minute amounts of humoral vasoconstricting agents, such as adrenaline (Meltzer and Meltzer, 1903 ; Freeman et al., 1934), which in limbs with an intact nerve-supply would have little or no effect. These peculiar properties of denervated blood-vessels may be regarded as particular examples of the more general phenomenon of denervation hypersensitivity (Cannon, 1939), and are believed to be due to inability of denervated tissues to bind circulating catecholamines (Hertting et al., 1961).

In the present experiments vascular responses characteristic of denervation hypersensitivity were clearly evident in those diabetic subjects who had absent vasomotor reflexes, thus confirming the earlier evidence of others (Doupe and Cherniack, 1950 ; Bárány, 1955 ; Bárány and Cooper, 1957 ; Stone et al., 1961). The peripheral blood-vessels of these subjects exhibited spontaneous tone which was independent of body temperature; they constricted in response to local cold or to a minute amount of adrenaline, but not to body-cooling; and they dilated in response to local heat but not to body-warming. Thus the abnormal pattern of vascular responsiveness in diabetic neuropathy is explicable on the basis of destruction of post-ganglionic sympathetic fibres (Bárány and Cooper, 1956 ; Keen, 1959), and no other lesion need be invoked. Therefore alternative explanations need to be sought for the observations of Martin (1953) and Sharpey-Schafer and Taylor (1960), which suggested to them that other lesions do exist.

The two types of neuropathic patients described by Martin (1953)-those with persistently warm and those with persist- 
ently cold limbs-were seen in the present study. However, his hypothesis, that these temperature differences were due to damage to vasoconstrictor and vasodilator fibres respectively, is no longer acceptable, for it is now generally agreed that cutaneous vasodilator fibres do not exist (Gaskell, 1956 ; Daly, 1962). Rather it is clear from the present experiments that the neuropathic limb stabilizes at either temperature, once imposed, and can be changed from warm to cold, or from cold to warm, by local chilling and heating. Therefore it appears to us that the groups described by Martin do not reflect a fundamental difference between subjects, but rather their degree of sensitivity to the prevailing environmental temperature.

The hypothesis of Sharpey-Schafer and Taylor (1960), that the abnormal vascular reactivity in diabetic peripheral neuropathy is due to damage to afferent rather than to efferent autonomic fibres, is not adequately supported by their evidence. It was based upon the finding of abnormal pressor responses to the Valsalva manœuvre and to tilting in subjects whom they believed to have normal thermal vasomotor responses. However, they examined the thermal vasomotor responses only in the hands of their subjects. Even in severe cases of diabetic neuropathy the hands are usually not involved. It is likely that the feet of their subjects were in fact affected.

The maintenance by a denervated limb of a temperature previously imposed by local warming or cooling can reasonably be explained on the basis of the interdependence between temperature and vasomotor tone (Freeman, 1935 ; Freeman and Zeller, 1937). Thus, for example, when vasomotor tone is diminished by local warming the flow of blood is increased, so that heat continues to be brought to the limb by the blood after the source of local heat is removed. Therefore the suppression of vasomotor tone is perpetuated. Similarly, when vasomotor tone is increased by local chilling the flow of blood is impeded, so that very little heat is brought to the limb and the increased vasomotor tone is maintained.

Vascular responsiveness in those subjects whose vasomotor reflexes were present but impaired was not fully examined in these studies. Because their feet showed a delayed vasoconstrictor response to body-cooling, and an enhanced vasoconstrictor response to adrenaline, it is reasonable to believe that they had undergone partial sympathetic denervation as a result of neuropathy. However, the patterns of response were variable, and it was not clearly ascertained whether partial arterial occlusion might not produce similar results. Also, the degree of cold sensitivity, if any, in these subjects was not determined. It seems desirable that these problems should be the subject of further studies.

Sympathetic denervation may occur in peripheral neuropathy associated with diseases other than diabetes, having been described in aneurine deficiency (Wilkins and Kolb, 1941 ; Birchfield, 1964), tabes dorsalis (Bárány and Cooper, 1957), and idiopathic orthostatic hypotension (Barnett and Wagner, 1958; Hickler et al., 1959 ; Engelman et al., 1964). In the present study it is curious that, in contrast to its common occurrence among diabetic subjects, complete sympathetic denervation did not occur in the group of subjects with pernicious anaemia, all but one of whom had peripheral neurological signs. Presumably this reflects a different distribution of nerve-fibre involvement in this disease. Its absence in this group of elderly subjects also supports the finding of Bárány (1955), that vasomotor abnormalities are not attributable to age itself.

In diabetic patients complete sympathetic denervation is very common. Thus in the present study it occurred in 16 out of 29 patients with, and in 3 out of 14 without, other neurological signs. These patients are frequently aware of the sensitivity of their peripheral vasculature to cold until their sensory perception is also destroyed. Several of them told us that when their feet became chilled they could be warmed again only by direct exposure to a source of heat. One woman volunteered the remark that after exposure to winter weather she immersed her feet in a tub of warm water, for otherwise they would remain painfully cold for many hours.

Whether cold-sensitivity contributes to the pathogenesis of trophic ulcers in diabetic patients it is difficult to say. It is reported that the blood-flow to denervated limbs is sufficient for the metabolic needs of the tissues (Freeman, 1935; Freeman and Zeller, 1937), but this might not be true if the bloodsupply were already compromised by arteriosclerosis. Also, pathological coldness might further impede the conduction of proprioceptive and pain sensations along damaged nerve fibres, and thus increase the danger of pressure necrosis at weightbearing sites. Until evidence is available on these points it seems well to recommend the avoidance of chilling of the feet by diabetic patients with peripheral neuropathy.

Finally, it is clear that cold-sensitivity may interfere with the assessment of the circulation in diabetic limbs. In particular, it is not always recognized (Mendlowitz et al., 1953 ; Megibow et al., 1953 ; Aagenaes, 1963) that absence or impairment of vasodilatation in response to body-heating or to ganglionic blockade does not necessarily indicate the presence of vascular occlusion. When vasodilatation is impaired, and particularly if any kind of operative intervention is being considered, it is imperative that tests of the peripheral circulation include the application of local warmth.

\section{Summary}

Peripheral vascular responsiveness was studied in 12 young healthy subjects, in 15 elderly subjects without diabetes, and in 43 subjects with diabetes. Twenty-nine of the diabetic subjects had neurological signs and 14 did not. Vasomotor responses to body-heating and cooling, local heating and cooling, and to the injection of adrenaline were measured by the continuous recording of digital skin temperatures.

Reflex vasomotor responses in the feet were completely absent in 16 of the diabetic subjects with, and in three of those without, other peripheral neurological signs. The pattern of vascular responsiveness in these feet was characteristic of denervation hypersensitivity. They exhibited autonomous vasomotor tone which was independent of body temperature, but which was readily augmented by local cold or by the injection of minute amounts of adrenaline.

Reflex vasomotor responses in the feet were present, but delayed, in four of the elderly non-diabetic subjects, and in nine of the diabetic subjects with, and two of those without, other neurological signs. It was not determined whether reactivity of this type was due to partial sympathetic denervation, partial arterial occlusion, or both.

The presence of cold-sensitivity due to sympathetic denervation in the peripheral vasculature of patients with diabetic neuropathy has not been generally recognized. It often causes discomfort, and sometimes pain; it may augment the development of trophic ulcers; and it may lead to unnecessary surgery by interfering with the assessment of the circulation in diabetic limbs.

\section{REFERENCES}

Aagenaes, Ö. (1963). Reports of the Steno Memorial Hospital and the Nordisk Insulinlaboratorium, Gentofte, Denmark, vol. XI. Ascroft, P. B. (1937). Brit. F. Surg., 24, 787.

Bárány, F. R. (1955). Acta med. scand., Suppl. No. 304.

- and Cooper, E. H. (1956). Clin. Sci., 15, 533. (1957). Ibid., 16, 275.

Barnett, A. J., and Wagner, G. R. (1958). Amer. Heart f., 56, 412. Berner, J. H. (1952). Acta med. scand., 143, 336.

Birchfield, R. I. (1964). Amer. f. Med., 36, 404.

Brody, M. J., and Dixon, R. L. (1964). Circulat Res., 14, 494.

Cannon, W. B. (1939). Amer. F. med. Sci., 198, 737 Cannon, W. B. (1939). Amer. F. med. Sci., 198, 737.
of Human Physiology, 13th ed.; edited by H. Davson and M. G. Eggleton, p. 229. Lea and Febiger, Philadelphia. Doupe, J. (1943). F. Neurol. Neurosurg. Psychiat., 6, 97.

and Cherniack, R. M. (1950). Canad. F. Res., 28, 222 (Sect. E).

Engleman, K., Mueller, P. S., Horwitz, D., and Sjoerdsma, A. (1964). 
Fatherree, T. J., and Allen, E. V. (1938). Arch. intern. Med., 62, 1015. Freemen, N. E. (1935). Amer. F. Physiol., 113, 384.

- Smithwick, R. H., and White, J. C.' (1934). Ibid., 107, 529.

Gaskell Zeller, J. W.' (1937). Ibid., 120, 475 .

Gibbon

Handelsman, M. B., Levitt, L. M., and Conrad, H. (1952). Amer. F. med. Sci., 224,34

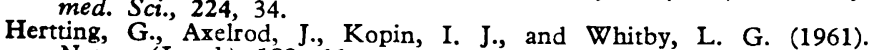
Nature (Lond.), 189, 66

Hickler, R. B., Thompson, G. R., Fox, L. M., and Hamlin, J. T. (1959). Nesw Engl. 7. Med., 261, 788 .

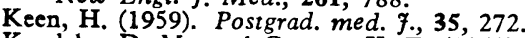

Kerslake, D. M., and Cooper, K. E. (1950). Clin. Sci., 9, 31.

Martin, M. M. (1953). Lancet, 1, 560.

Megibow, R. S., Megibow, S. J., Pollack, H., Bookman, J. J., and

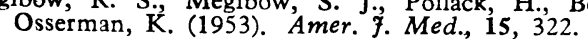

Meltzer, S. J., and Meltzer, C. (1903). Amer. 7. Physiol., 9, 252. Mendlowitz, M., Grossman, E. B., and Alpert, S. (1953). Amer. F. Med., $15,316$.

Meyer, R. T. (1941). Helv. med. Acta, 8, Suppl. No. 7, 18.

Odel, H. M., Roth G. M., and Keating, F. R. (1955). Diabetes, 4, 92.

Pickering, G. W. (1932). Heart, 16, 115.

Pickering, G. W. (1932). Hear 1 .

Pryce, T. D. (1887). Ibid., 2, 11

(1893). Brain, 16, 416 .

Richards, R. L. (1946). The Peripheral Circulation in Health and Disease. Livingstone, Edinburgh.

Rundles, R. W. (1945). Medicine (Baltimore), 24, 111.

Sharpey-Schafer, E. P., and Taylor, P. J. (1960). Lancet, 1, 559.

Shumacker, H. B. (1942). Bull. Fohns Hopk. Hosp., 71, 1.

Stone, D. B., Talley, R. B., and Eckstein, J. W. (1961). Circulation, 24, 1051.

Wilkins, R. W., and Kolb, L. C. (1941). Amer. 7. med. Sci., 202, 216.

\title{
In Vitro Thrombosis and Platelet Aggregation in Myocardial Infarction
}

\author{
N. G. ARDLIE,* M.B., B.S. ; RAELENE L. KINLOUGH, $†$ M.B., B.S. \\ C. J. SCHWARTZ, ${ }^{*}$ M.D., M.R.A.C.P., M.C.P.A., M.C.PATH.
}

Brit. med. F., 1966, 1, 888-891

In 1958 Chandler showed that when recalcified citrated whole blood is made to flow in a closed rotating circular plastic loop it does not clot but forms a discrete mass with the histological features of a thrombus. This observation, confirmed by Poole (1959), prompted us to employ the Chandler tube in an attempt to determine if the circulating blood of patients with, after, or prone to thrombosis shows any propensity to abnormal thrombosis in vitro. As part of such a study we report our observations on 50 patients with myocardial infarction and 52 healthy controls.

\section{Materials and Methods}

Subjects Studied.-The age distribution of the 102 subjects studied is detailed in Table I. Control subjects consisted of our colleagues, laboratory assistants, and volunteer hospital porters in whom there was neither clinical nor electrocardiogaphic evidence of myocardial infarction. Patients with myocardial infarction were selected from both hospital in-patient and outpatient clinics, and all had clinical, laboratory, and electrocardiographic evidence consistent with this diagnosis. Ten of the 50 patients with myocardial infarction and 6 of the 52 controls were women, numbers which were too small to permit a separate sex analysis. Most subjects were studied for six or seven consecutive days.

Blood Samples.-Antecubital venous blood was collected each morning, with the aid of venous occlusion and mild forearm exercise, by means of siliconized glass syringes and 19-gauge needles. Nine parts of blood were added to one part of $3.8 \%$ trisodium citrate in siliconized glass centrifuge tubes, and were mixed gently by inversion. Citrated platelet-rich plasma was prepared by centrifuging at $350 \mathrm{~g}$ for 15 minutes. On the first day of study samples for total serum cholesterol and plasma fibrinogen were collected.

Total serum cholesterol was estimated with a Technicon Auto-Analyzer, a slight modification of the method described by Zlatkis, Zak, and Boyle (1953) being used.

Plasma fibrinogen was determined by the method of Soles and Roman (1957).

\footnotetext{
- Department of Pathology, Institute of Medical and Veterinary Science, Adelaide, South Australia.

t Department of Medicine, University of Adelaide, South Australia.
}

The Chandler apparatus was essentially similar to that first described by Chandler in 1958 and subsequently modified by Poole (1959). A circular disk of perspex was attached to a larger perspex disk inclined at 30 degrees from the horizontal and mounted on an electrically driven motor rotating at 9 r.p.m.

One millilitre of citrated whole blood or platelet-rich plasma was placed in a closed circular loop of polyvinyl chloride tubing (Portex, NT/F) having an internal bore of $3 \mathrm{~mm}$. This was recalcified by the addition of $0.1 \mathrm{ml}$. of $\mathrm{M} / 4$ calcium-chloride solution, at which time a stopwatch was started. The tube was closed with a short cuff of slightly larger tubing (Portex, $\mathrm{NT} / \mathrm{K}$ ), the closed loop fitted around the smaller perspex disk, and the motor started. The latter disk had a short recess to accommodate the cuff. Each loop had a length of $37.9 \mathrm{~cm}$. $(r=6 \mathrm{~cm}$.), and with rotation the column of blood or plasma had a constant linear velocity of $340 \mathrm{~cm}$. $/ \mathrm{min}$. A fixed protractor was mounted beneath the perspex disks, and the angle of the advancing column of blood or plasma was recorded at 30 -sec. intervals. Changes occurring at the advancing edge were observed through a wide-angle stereoscopic dissecting microscope under bright oblique illumination.

All experiments were performed at room temperature maintained within the range $22-25^{\circ} \mathrm{C}$.

Thrombus Formation Time.-This term, coined by Connor and Poole (1961), relates to the time at which the angle of the advancing edge of blood or plasma changed.

Whole-blood Thrombus Length.-In all cases rotation continued for seven minutes after an angle change had occurred. The thrombus formed was emptied into a Petri dish containing $0.9 \%$ saline, and its length was measured to the nearest milli-

TABLE I.-Age Distribution of the 102 Subjects Studied. Patients with Myocardial Infarction are Subdivided Into Those Receiving or not Receiving Anticoagulant Therapy

\begin{tabular}{|c|c|c|c|c|c|c|c|}
\hline \multirow{2}{*}{$\begin{array}{c}\text { Subject } \\
\text { Categories }\end{array}$} & \multicolumn{7}{|c|}{ Age Group (years) } \\
\hline & $11-20$ & $21-30$ & $31-40$ & $41-50$ & $51-60$ & $61-70$ & $71-80$ \\
\hline Controls & 3 & 9 & 12 & 15 & 10 & 3 & - \\
\hline $\begin{array}{c}\text { Myocardial infarct: } \\
\text { Anticoagulant } \\
\text { No anticoagulant } \\
\end{array}$ & $\overline{1}$ & - & 1 & $\begin{array}{l}4 \\
1 \\
\end{array}$ & $\begin{array}{r}15 \\
4 \\
\end{array}$ & $\begin{array}{r}3 \\
14 \\
\end{array}$ & $\begin{array}{l}1 \\
6 \\
\end{array}$ \\
\hline $\begin{array}{l}\text { Total myocardial } \\
\text { infarct } \ldots\end{array}$ & 1 & - & 1 & 5 & 19 & 17 & 7 \\
\hline
\end{tabular}

